\title{
Sound Ecologies
}

\section{MiCHELLE DUfFY}

Late summer evening. With the windows rolled down, the bellbirds chime around me-ping, ping, ping-ping - as I turn right into Wallaga Lake Road and drive the last few kilometres to town through the Bermagui State Forest. I'm here to begin a research project with a colleague. We're asking people to identify the sounds they feel to be integral to them in making this place of Bermagui meaningful. The bellbird's call is to be a ubiquitous presence, accompanying us during our visits as we talk to residents around Bermagui. Yet, apart from one young local who had only just returned from study in Sydney, bellbirds were rarely mentioned, reminding me that we are each selective in what we hear, that we have 'deaf spots' in which habituation often deafens us to our local soundscapes. ${ }^{1}$ Maybe, too, we need to distinguish how we hear from how we listen. Jean-Luc Nancy defines hearing in terms of understanding and comprehension, while listening (the French term écouter) is an experience of sound in which we don't fully interpret the experience. ${ }^{2}$ Listening, then, is perhaps more aligned to our emotional and bodily responses than to our sonic environments. Such a framework has implications for understanding the role of sound in social processes and place-making. Sound is not simply a background to the (visual, social) world. Instead, our social relationships help 
comprise particular spatial contexts, and sounds provide a range of affective affordances appropriated by individuals to deeply inform not only how to move and mingle but crucially also how to think. ${ }^{3}$ The meanings we attribute to those sounds we do note reflect our values, our lives, our aspirations. ${ }^{4}$ Even so, the pounding of the surf driven by changing tides, frogs heralding rain, wattlebirds amongst the grevillea, lyrebirds and their clever imitations, even the hum of everyday life resounding in coffee machines, V8 engines and a fridge-what to make of the recorded cacophony that our participants used to describe Bermagui's everyday soundscapes? And can these sounds offer insight into the idiosyncrasies of relationships between people and place, and so tell us something of the rural in contemporary Australia?

Discussions about what the rural is invariably focus on notions of spatial location, of inhabiting spaces apart from that of the metropolitan. The rural landscape is deeply embedded in our images of what it means to be Australian-in which 'the rural is often positioned on the national scale as a symbolic site for authentic national values'5-nonetheless, our intellectual framing of rurality as something outback and beyond has significant implications for our understanding of these spaces. Indeed, we lack an adequate intellectual framework for comprehending what we mean by rurality, and discussion on what the rural is continues to provoke debate, and not only within Australia. A rural imaginary lies at the heart of many constructions of national identity around the globe, a space in which a nation's core image of itself is positioned within an often homogenous people's 'honest' and 'authentic' relationship to nature. ${ }^{6}$ Even locating where we might find the rural raises difficulties. For example, a recent rural health workforce audit undertaken by the Rudd federal government has led to concerns that a new distance-based measure for remoteness will change official recognition of rural areas and so disadvantage smaller and more densely populated Australian states. ${ }^{7}$ In this framework, then, we see rurality defined in relatively simple terms, a conflation of geographical remoteness and the actual numerous means whereby people live and express their rural lives. Yet, as many are aware, the ways in which we inhabit space in the contemporary world troubles such spatially determined definitions. Rather, what we can observe is that rural lives are stretched, interrupted and woven across places and time. 
In the sound diaries gathered and the ensuing interviews, many of the participants in our project turn out to be relatively recent arrivals in Bermagui: examples of the phenomena of sea- and tree-changes. ${ }^{8}$ Their soundings of place tell much of the emotional and affective processes involved in searching for home and community within their slice of the Australian rural landscape, while careful listening to their responses suggests that defining the rural (and, hence, the what-isnot-rural) raises complexly entangled ideas of place. What is meant by concepts of belonging, home and community are complicated by allegiances, histories, relations and feelings stretched across personal and public spheres as well as rural and nonrural spaces.

Down-sizing and sea- and tree-changes also point to changes in the Zeitgeist. Many commentators have noted that in the West generally there has been a sense of loss of meaningful community. Some, such as Richard Sennett, argue that the new global economy has meant less certainty and increased anxiety, leading to a much more fragmented sense of identity. ${ }^{9}$ In response to this sense of fragmentation and disconnection there has been a shift to ways that create greater emotional attachment, ways that reconnect us and remake our ties of belonging. Popular culture taps into these concerns, and in numerous lifestyle magazines we're told the oft-repeated stories of those who've made the change from 'a life dictated by the clock' to one of 'peace and solitude of being in the natural environment'.10 We are urged to create our own sanctuary, regenerate, rejuvenate, to return to the simple but important things of life: family, friends, neighbours. This shift brings to mind the potency of our image of home within what Gaston Bachelard calls the 'virtues of shelter ... so simple, so deeply rooted in our consciousness'.11 In a recent issue of M/C Journal, Andrew Gorman-Murray and Robyn Dowling write:

Home is powerful, emotive and multi-faceted. As a basic desire for many, home is saturated with the meanings, memories, emotions, experiences and relationships of everyday life. The idea and place of home is perhaps typically configured through a positive sense of attachment, as a place of belonging, intimacy, security, relationship and selfhood. 12

Invariably emotional, yet it is the bodily and affective responses-those experiences beyond words, or perhaps the tacit, embodied and personal knowledge we hold about place ${ }^{13}$ - that have the potential to open up recognition of the body's process 
in understanding place as home, a perception of 'withness' in our relationship to place that regulates our cognisance of the world. ${ }^{14}$ Woven through this relationship is a politics of affect no less vital than that found within cities, ${ }^{15}$ where keenly felt battles around saving place and redressing lack appear alongside increased celebrations of marking out 'our' rural home places. In listening to the collections of sounds and stories about (and through) sounds, this article explores the ways in which such a focus can draw attention to the intuitive, emotional, and affective processes of home and place-making and what this may mean in a rural landscape. Drawing on Nigel Thrift's concept of an ecology of place and Jean-Paul Thibaud's ecological approach to perception, I suggest that contemporary heightened concerns with regards to loss and lack in rural Australia have led to a nascent emotional ecology-one in which individual and intimate connections to the rural require a rethinking of how we live community and belonging. ${ }^{16}$ We need to better understand what these oft-used concepts of community and belonging mean in our day-to-day. This means that we need to listen carefully to the deeply personal and emotional descriptions of place, relationality and the very 'thinginess' of being in order to uncover what is often so difficult to articulate in words.

Bermagui, a town of around two thousand people located about four hundred kilometres south of Sydney, has long been a tourist destination. 'Discovered' in the 1930 s as the place for big-game fishing of marlin and tuna, the population now swells to seven thousand people during the summer months in search of what is described in New South Wales tourism literature as 'paradise'. ${ }^{17}$ Bermagui is also a sea-change town with two noticeable demographic characteristics: an increasing proportion of people aged fifty-five and over, many of whom are retirees, and that almost a quarter of the population has 'down-shifted' in order to redress work-life balance, such as spending more time with family and friends. ${ }^{18}$ The seven women and three men who took part in this project were aged from their twenties to their sixties, and could be categorised as 'white' and 'privileged', insofar as they generally have an Anglo-Celtic heritage, are tertiary educated, have travelled the globe, and have chosen to live on the south coast of New South Wales. 
The town's main street, Coluga Street, looks across to the waterfront and Dickinson Park, the venue for local sporting activities and celebrations. Along this small shopping strip are a number of cafes, a hotel, a bakery and fish co-op, even a beauty salon. Art spaces, heritage attractions, restaurants and festival spaces are recent additions around the town, catering for the arrival of, particularly, older residents from Canberra, Melbourne and Sydney. Much of its earlier European heritage - the old wharf and many of the original buildings related to the timber and fishing industries-has been lost. Lost, too, is much of the local Indigenous heritage, that of the communities now known as the Yuin nation, living in what was then called Two-Fold Bay by European whalers. ${ }^{19}$ Material cultural heritage is not the only loss current residents are concerned with. Reading local newspapers and talking to residents over coffee, the changes brought about by the influx of tourists and newcomers produces ambivalent responses. While the economic advantages for local businesses are welcome, the actual changes to social, cultural and environmental spaces are not, as we hear in this exchange between two Bermagui residents originally from the United Kingdom:

KW: The only problems we do get with them [tourists] is the ones that come down and are from the city, they buy a place-they've obviously got lots of money. They come in and buy a place and then want to change it to how the city is. They left the city and came here-

DW: for a change-

KW: - to get away from all that and then they want the city back then! And we say, well, no we don't need that.20

This is a well-known narrative, to be sure, in small rural and coastal towns now subject to rapid transformation, where community and place are almost jealously guarded from the influx of contemporary urban life. This tension in Bermagui, as in many of Australia's coastal towns, is attributed to the movement of sea-changers, who, although seeking a more relaxed lifestyle, still expect the cultural amenities of major cities. Even so, these residents do acknowledge the historical and cyclical patterns of change in rural places, as another project participant, SB, explained:

I think it is a lot of people who come to live here just traditionally have lived in town [i.e. Bermagui] and it was a cheap place to live and an easy 
place to live and you're not confronted with anything. And, you know, there's always been a group who come in and have got strong opinions about change and are more progressive and there's more progressive people now. And there's actually a huge dividing line in town over development issues and things between those people-it's not that there's a group of people who are anti-development, it's just that they want sustainable development. But there are people who feel very uncomfortable and threatened and angry about that. ${ }^{21}$

Tensions between longer established residents and those who have more recently arrived draw attention to the meanings invested in this rural, idyllic landscape. And, although SB's use of the term 'sustainable development' refers to a specific set of politics, all involved have some clear sense of wanting to hang on to their particular view of the rural imaginary as home. These passionate debates within Bermaguiwhether around questioning the timber and fishing industries, real estate and tourist development, sustainability and climate change-and hence debates about the meaning invested in this place, are framed by a powerful affective register. ${ }^{22}$ Uncovering these emotional registers is methodologically difficult yet empirically important, for, as Nigel Thrift argues, there is a crucial spatial politics of affect made manifest within the everyday, and without a means of critical engagement with such a politics we cannot understand the new collectives that arise. He explains that in other (than) words, emotions form a rich moral array through which and with which the world is thought and which can sense different things even though they cannot always be named'.23 In addition, as Les Back argues, we need to take notice of such seemingly small details as they can tell us much about the larger social forces operating within the everyday. ${ }^{24}$ What is suggested by both Thrift and Back is that there is a shared understanding of the everyday arising within particular social contexts that more often than not escapes our conscious engagement, but that has a significant impact on the ways we relate to others. ${ }^{25}$ The use of sound diaries in this project is a means to access such a politics. Asking participants to consider the sounds of their everyday is a means to capture what residents feel are the essences of their lives in Bermagui, and to uncover the embedded narratives of place and community they hold through the personal connections they make with, through and in this locality. 
Each participant was equipped with a digital recorder the size of a mobile telephone and asked to record sounds that meant something to them about their everyday life in Bermagui. Then participants were asked to take part in a conversation about what was recorded. While the use of diary methods is not new-written, photograph and video diaries have been used in a number of disciplines-asking participants to record meaningful sounds is an opportunity to experience place through non-visual references, and this focus, as recent research demonstrates, provides a means to explore the intuitive or affective aspects of sounds in our social life. ${ }^{26}$

When asked to make their sound diaries those who participated were, perhaps not surprisingly, drawn to sounds of the non-human world and, more specifically, to sounds that were located within the landscape of Bermagui. These sounds provide a vital clue as to how people make sense of Bermagui as home. Many revealed their ongoing concern to protect their nature, their home, particularly from developers who, they feel, are attempting to remake Bermagui as a scaled-down form of the city. As DW tells me:

You have to make that decision. If you want to move to somewhere like Bermagui from the city, you can't expect to have the city life in Bermagui. You're either coming here 'cos you like the tranquillity and the lifestyle of Bermagui and a bit laid back, but beautiful all the same and unspoilt. Or you get back into the rat race of the city where there's all the noise and the pollution and everything else. ${ }^{27}$

What appears to 'make' Bermagui in these discussions is the non-human, understood by participants as untouched or unspoilt Nature. Yet while the surf, birdcalls, rain, and frogs could be categorised in terms of a generic set of nature sounds, in the follow-up interviews what participants actually suggested in their responses was a much more nuanced-and human-centred-hearing of place. For example, one of the first things DW and KW talk about when asked to reflect on the sounds of their home was the sound of birds:

KW: If you really want to find out what a place is like, get up before the sparrow farts and listen, and you'll hear it come alive. That bird you usually hear first thing in the morning-

DW: $\quad$-the wattle bird- 
KW: $\quad$-the wattle bird-and he wakes the forest up. And then after that, then they all start.

DW: $\quad$ The magpies in the area, you know, then usually the other birds don't come around until the sun's up-

KW: $\quad-$ no-

DW: - but the wattle bird's the early bird. And we've got possums here. And they travel between Leo-he's next door-to mine and next door but one, and they go for the bird seed as well. 'Cos we all feed the birds. ${ }^{28}$

There's a delightful rhythm in the way each interjects and reiterates the telling of this, and within this exchange they both perform the knowing of their home spaceas KW says, 'if you really want to find out what a place is like...' followed by their litany of named birdcalls and the ways these connect to the unfolding of dawn. Many other participants also displayed such an intimate listening to place, and most often when talking about the surf (although not unexpected given the town's location), as found in CB's description:

Another thing that's different here from, and characteristic of Bermi-and a lot of coastal towns along here-is the sound of the surf. And there are different sounds here of surf in Bermagui. The sound of the surf, a rather more gentle surf, you hear around here at what's called the headlands area. And there's the sound of the surf when there's a swell coming from north-at Beares Beach—where it crashes on the rocks and makes a very, very loud sound. And you wouldn't want to live-for me anyway-near anywhere sort of near Beares Beach down there. Even though they have some very expensive sort of properties down there. Because, if the surf's, if the swell's coming in a particular direction, they're very, very loud crashes as it hits great big rocks and that sort of thing down there you know. ${ }^{29}$

Like KW and DW, CB describes a very detailed knowledge of the surf, with certain surf sounds associated with very specific parts of the coastline. CB also links these sounds with certain attributes of who would wish to live in these places. In these descriptions of sound and place we begin to discern how people map themselves into these spaces. In their recounting of the bird sounds at dawn, KW and DW point to their own personal mappings of home within particular networks. For example, 
KW and DW's list of birdcalls also maps through connections with neighbours of 'like-mindedness', as in the description of Leo ('he's next door-to mine and next door but one') and who also feeds the local birds and possums. Home and nature are therefore mapped into networks of the non-human and human in quite personal ways that then produce a sense of belonging in that place.

However, it is not just non-human sounds that are significant to these processes of marking out networks of belonging. Human sounds also serve to connect participants to Bermagui in unexpected, almost paradoxical ways. When asked to record sounds meaningful to her everyday place, SB recorded her printer, saying as she did so:

This is my printer, printing out something, and I love this sound because it makes me feel like I'm getting something done. And I can leave my office and go outside and be in the beautiful world ... you might be able to hear the pitter patter of rain outside. And I feel like I'd just like to walk around and splash in it really. And this place when it's wet certainly takes on a new life, which I love. ${ }^{30}$

This is a less direct connection to the specifics of place; nonetheless, SB goes on to talk about how, since moving to Bermagui, she wants to be outside. 'I wasn't a nature person,' she adds,

Nature was something you looked at but didn't participate in ... it's sort of one dimensional unless you're in the outdoors. And it's a very gentle environment and it is very nourishing and I don't get any of the nourishing unless I'm in it ... And I didn't really understand being in nature before. ${ }^{31}$ For those who participated in recording sound diaries, this being in nature was considered one of the significant things about what it means to live in Bermagui, and they strongly asserted in conversation that this non-human world is to be cherished and protected.

Not all sound diaries contained sounds assigned such positive attributes. A number of sounds were classified as noise and experienced as intrusive elements breaching Bermagui's tranquillity. Inevitably these sounds were of the human world. For example, the sound recording made by L, a young adult from neighbouring Bega, of the coffee machine in the cafe where he works, a sound he 'hated',32 or SB's fridge, which she notes is 'big and clumsy and it takes too much 
power and it annoys me'. ${ }^{33}$ These sounds of noise reflect a range of personal politics, as in SB's active involvement as an activist with a practical desire to address issues of the impact of carbon on climate change. However, the sound diaries and conversations triggered by these recordings do not suggest belonging to Bermagui is easily or only represented through the sounds of the non-human world. SB's discussion around the sounds of her printer suggests a more subtle relationship between categories of non-human and human worlds and the ways in which individuals create relationships of belonging to Bermagui. Moreover, the complexity of emotional responses to sounds of the human world is evident in CB's discussion of what comes to mind when he hears an early Holden car-model travelling through Bermagui's streets:

Another sound that reminds me of something is the sound of what's called a two fifty-three V8-it's an old model Holden. It's one of their early V8'sand they have a characteristic sound. And we had a two fifty-three in the family-which I gave to T-he's my youngest, and he drove around in this two fifty-three. And he quite liked it but it was only a two fifty-three, so it wasn't quite powerful enough for him. So he ended up selling it and both of us have regretted that since. Not that we have any ill-feeling about it but I think of this when I hear this-I don't have to see it, I can hear it and think that's the two fifty-three and, you know, as it's going past. I think of T and, you know, my youngest and those sorts of interactions we had around the car. When I gave him the car and he then when gave it up and thought it was going to improve his lot, which he didn't do-he's got himself another old car, which has cost him a fortune. It's not as good. ${ }^{34}$

We start to hear in this response how the ways in which people listen and respond to place is intricately woven into their personal geography, history and social networks that extend beyond the time-space of town's borders. In this instance, the sound of a V8 engine reminds CB of his relationship with his youngest son, and he talks of the regret both felt when that car was no longer a part of how they interact. This engine sound reconnects CB into deeply personal networks of family, overlaying Bermagui's streets with memories of another home place. These focuses on sound, then, give us a glimpse into the diverse relationships between listening, emotions and belonging, and how we may begin to gain some, albeit partial, access 
to a spatiality of feelings. As Nichola Wood and Susan Smith suggest, this is significant in how we make sense of the world. ${ }^{35}$ Our emotional responses locate us within specific networks of human and non-human relationships, and of multiple time-spaces, that then give rise to a place in which we create a feeling of home and belonging.

As these sound diaries suggest, sound is not simply a physiological outcome of hearing sonic qualities and, therefore, merely a background to what is happening in the everyday. Rather, what often goes undetected are the ways in which certain sounds are accorded particular personal and ideologically loaded meanings that have an emotional impact. For example, sound only becomes meaningful when listened to in situ, as in the example of the throb of a V8 engine and how this can emotionally connect an individual to another. Jack Katz puts the embodied process of affect in this way, 'the doing of emotions is a process of breaking bodily boundaries, of tears spilling out, rage burning up, and as laughter bursts out'.36 Affect and emotions open us up to the world and to others. If we focus on what is seen and talked about, rather than what is heard-and the very personal meanings attributed-what can be obscured are the more nuanced and complex ways that interconnections between people and place are constituted and mediated, and the ways emotion and affect are significant to these processes. As many have pointed out, our more usual emphasis on representational practices also persuades us to perceive ourselves as separate beings, disconnected from our world. ${ }^{37}$ Yet, as these sound diaries demonstrate, a focus on sound directs our attention to processes of connectivity and the networks in which we may feel a sense of belonging (as well as instances of alienation).

\section{$-4$}

In a recent posting on the online site TED, Renny Gleeson, of the advertising agency Wieden and Kennedy, talked about how we share narratives in order to make a community; that 'what we share becomes the context in which we live and who we are'. ${ }^{38}$ In the sounds collected and in conversations with the participants, what is shared are relations between the individual's inner and outer worlds, and in both the collection and telling of the collection we can gain some partial access to affective embodied ways of mapping the subject in place. Such relational 
conceptualisations of home are, as Gorman-Murray and Dowling point out, 'a fusion of the imaginative and affective ... an actual location which can embody and realise our need for belonging, affirmation and sustenance'. ${ }^{39}$ Even so, these mappings of home and belonging are never simply about social location and constructions of identity. As the examples discussed here demonstrate, these various mappings structure individuals as social and spatial beings, creating a form of domestic (or perhaps domesticated) space in which people feel at home. Rather than being limited by geographical or temporal locations, these are actually intertwined in a 'set of intersecting and variable ideas and feelings, which are related to context, and which ... extend across spaces and scales, [that] connects places'.40 While belonging is about emotional attachment, about feeling 'at home' and 'safe', we do belong in many different ways and to many different objects, people and places. ${ }^{41} \mathrm{We}$ also experience such belonging in a variety of forms, from an abstract feeling about what we may think of as our place or community to a much more concrete notion of belonging in which we participate in activities that display our allegiances and affiliations. In thinking about what constitutes the rural, we need to consider the affective registers operating in place-making. As Kye Askins argues, it is not simply that nature can be conflated with the rural, but that we 'need to move beyond understanding nature and place as only socially constructed, and consider how landscape is sensed'. ${ }^{2}$ A politics of belonging takes these feelings of attachment in order to create belonging in particular ways or to particular collective identities, and these attachments and identities arise in the narratives that people tell about themselves. ${ }^{43}$

The significance of sound in such an approach is that it enables us to consider how place, home and belonging are constituted through affect and emotion. First, sound is a means of fixing ourselves to place while in a state of moving (both physically and metaphorically) through spaces, ${ }^{44}$ as the narratives of nature and sound told by KW, DW and CB demonstrate. The space in which these audible interactions between self and place occur enables a connection to that place, as this meeting of human and non-human creates a means to be emplaced, where 'home enfolds and carries some sense of desire for positive feelings of attachment'.45 Second, a focus on sound brings us back to our selves and our place so that we recognise we are not separate and autonomous entities but interlinked, so 
generating a possibility of belonging that then often spills out into helping individuals make sense of their position within the everyday. These sonic processes, then, are both personal and communal, and significant to our connection to place and to others. Finally, sound problematises any neat separation of self and non-self, of object and subject, as it gives the illusion of our continuity with the world as sound passes through and into the body. As CB's deceptively simple description of the sounds around his house demonstrate, 'Coming up Murrah Street, [the cars are] a little bit in my personal space but still, you know, the sound of the cars going through the rain water tells me that everything's in order and that's how it all should be'. 46

Nigel Thrift's elaboration on what he has called non-representational theory is useful in tracing these affective processes. His relational approach signals the interconnectedness of place through practice rather than representation. ${ }^{47}$ Such a perspective-what Thrift calls an ecology of place-also helps in understanding how places come to be shaped, understood and defined. Bermagui is rural because of the interactions of a wide range of entities-material, social, physical, cultural, human and non-human-that are actively embodied in the knowledges of people in their everyday lives. ${ }^{48}$ This does not mean this is a rural town because it is in a particular geographical location, although this is a contributing factor. Rather, it is the dialogic set of relations between self, place and community located within a global matrix of other places and social relations that then go into constituting Bermagui as rural. This is significant to conceptualising the dynamics of rural placemaking processes that avoids simple dichotomies around ideas of the urban/rural, culturally diverse/ monocultural frameworks used to talk about rural spaces. As Kye Askins suggests, to use the more progressive concept of transrurality 'both encapsulates the specificities of place and is open to mobility and desire' such that the notion of the rural as an exclusionary site of (white) national identity is challenged. ${ }^{49}$ In this framework for thinking about place, belonging is an affective quality in and through which we orient ourselves within noise, silence and vibrations, and consequently come to feel 'in place' through the psychological and physiological responses of our bodies. ${ }^{50}$ Out of this arises our intensely personal relations to place that are taken up in more public ways; the emotional ecology of belonging. 
We need to recognise, then, that our personal and subjective experiences of place are not trivial things. Our perception of places, and feelings of connection to them, start with each of us as perceiving subjects, which, as Jean-Paul Thibaud points out, positions us 'right in the middle of the world [we] perceive ... that links and unifies the many components of a situation'.51 The sound diary method enables participants to consider how the personal is political, how our experiences and the emotions they trigger are integral to 'conceptions of self identity and spatial practices through landscape as performed, enactive and emergent'.52 It is from such an emplaced strategy that we can consider our shared understandings and desires for a rural imaginary. The 'big picture' concerns such as global warming, salinity and the movement of youth out of rural areas need to begin with acknowledging the immediacy of our relationships and the significance of such personal dynamics that nonetheless extend beyond the local. 53

When asked to record her everyday sounds, P, like many of the participants, recorded rain, the surf and birdcalls. But she also included the sounds of her dog as she gives it a bone to chew on. You can just make out what she whispers-'Here! Good boy!' - before a crunching of bone resonates. 'That's my beautiful dog chewing a fresh bone,' she says clearly into the microphone. In the background, you can just make out the ping of the bellbirds.

Michelle Duffy is a sociology lecturer in the School of Humanities, Communications and Social Science at Monash University. Her main research interests include the intersections of poststructuralist thought with festivals, music, community, place and the body.<Michelle.Duffy@arts.monash.edu.au>

\section{-ACKNOWLEDGEMENTS}

Appreciation is extended to Sheena Boughen, director of the Four Winds Festival Board; the Australia Research Council's Cultural Research Network; to the participants who kept sound diaries; to Gordon Waitt for collegiality and comments; to Lisa Slater for reading an early draft of this paper; and to two anonymous reviewers for their comments. 


\author{
-NOTES \\ 1 Barry Turax, Acoustic Communication, Ablex Publishing, Westport, CT, 2001, pp. 98-100. \\ 2 Jean-Luc Nancy, Listening, Fordham University Press, New York, 2007. See also Paul Simpson, “'Falling \\ on Deaf Ears": A Postphenomenology of Sonorous Experience', Environment \& Planning A, vol. 41, 2008, \\ pp. 2556-75. \\ 3 Tia DeNora, Music in Everyday Life, Cambridge University Press, Cambridge, 2000; Jean-Paul Thibaud, \\ 'From Situated Perception to Urban Ambiences', Centre de recherche méthodlogique d'architecture \\ (Nantes), First International Workshop on Architectural and Urban Ambient Environment, 6-8 \\ February 2002, Nantes, Cerma, Ecole d'architecture, 2002. Support CD; Gordon Waitt and Michelle \\ Duffy, 'Listening and Tourism Studies', Annals of Tourism Research, forthcoming. \\ ${ }^{4}$ For a range of examples of this, refer to Ros Bandt, Michelle Duffy and Dolly MacKinnon (eds), Hearing \\ Places: Sound, Place, Time, Culture, Cambridge Scholars Publishing, Newcastle-upon-Tyne, 2007. \\ ${ }^{5}$ Andrew Gorman-Murray, Kate Darian-Smith and Chris Gibson, 'Scaling the Rural: Reflections on Rural \\ Cultural Studies', Australian Humanities Review, 45, 2008, p. 43. \\ 6 For example, there has been a recent critique in the geographic literature of English rurality and its \\ association with an assumed white English identity, including Kye Askins, 'Crossing Divides: Ethnicity \\ and Rurality', Journal of Rural Studies, vol. 25, 2009, pp. 365-75; Caroline Knowles, 'The Landscape of \\ Post-Imperial Whiteness in Rural Britain', Ethnic and Racial Studies, vol. 31, 2008, pp. 167-84; David \\ Matless, Landscape and Englishness, Reaktion, London, 2008; Ruth Panelli, Phil Hubbard, Brad \\ Coombes, Sandie Suchet-Pearson, 'De-centring White Ruralities: Ethnic Diversity, Racialisation and \\ Indigenous Countrysides', Journal of Rural Studies, vol. 25, 2007, pp. 355-64; Divya Tolia-Kelly, \\ 'Mobility/Stability: British Asian Cultures of 'Landscape and Englishness', Environment and Planning A, \\ vol. 38, 2006, pp. 341-58. A similar critique is developing within Australian rural studies, see for \\ example, Kirrily Jordan, Branka Krivokapic-Shoko and Jock Collins, 'The Ethnic Landscape of Rural \\ Australia: Non-Anglo-Celtic Immigrant Communities and the Built Environment', Journal of Rural \\ Studies, vol. 25, 2009, pp. 376-85. \\ 7 Leo Shanahan, 'Zone Plan “Will Close” Hospitals in Rural Areas', Age, 31 January 2009, p. 9. What is \\ now characterised as rural and regional could be reclassified as 'inner regional' and, hence, these \\ places may be ineligible for rural-targeted grants. \\ 8 For a fuller discussion of the methods used, refer to Michelle Duffy and Gordon Waitt, 'Sound Diaries: \\ A Method for Listening to Place', Aether: The Journal of Media Geography, forthcoming; Waitt and Duffy, \\ forthcoming; Nichola Wood, Michelle Duffy and Susan J. Smith, 'The Art of Doing (Geographies of) \\ Music', Environment and Planning D: Society and Space, vol. 25, no. 5, 2007, pp. 867-89. \\ The terms 'sea-change' and 'tree-change' refer to Australian forms of internal migration driven by \\ lifestyle and environmental, rather than economic, factors. For a critique of these phenomena, see \\ Nicole Gurran and Ed Blakely, 'Suffer a Sea Change? Contrasting Perspectives Towards Urban Policy \\ and Migration in Coastal Australia', Australian Geographer, vol. 38, no. 1, 2007, pp. 113-31. \\ ${ }^{9}$ Richard Sennett, The Culture of New Capitalism, Yale University Press, New Haven, 2006. \\ 10 Barbara Sweeney, 'Hot to Trot', Australian Country Style, September 2006, p. 13; Virginia Imhoff, 'The \\ Gem in the Corner', Australian Country Style, September 2006, p. 97. \\ 11 Gaston Bachelard, The Poetics of Space, trans. M. Jolas, Beacon Press, Boston, 1994 (1958), p. 12. \\ 12 Andrew Gorman-Murray and Robyn Dowling, 'Home', $M / C$, vol. 10, no. 4, 2007. Online \\ $<$ http://journal.media-culture.org.au/0708/01-editorial.php> \\ 13 Michael Polanyi, The Tacit Dimension, University of Chicago Press, Chicago and London, 2009. \\ 14 Edward Casey, The Fate of Place: A Philosophical History, University of California Press, Berkeley, \\ 1997, p. 214
}


15 Nigel Thrift, 'Intensities of Feeling: Towards a Spatial Politics of Affect', Geografiska Annaler B, vol. 86, 2004, pp. 57-78. Thrift argues that cities are experienced in terms of the 'utter ubiquity of affect as a vital element', yet he notes there has been little serious study in this field.

16 Nigel Thrift, 'Steps to an Ecology of Place', in Doreen Massey, John Allen and Philip Sarre (eds), Human Geography Today, Polity Press, Cambridge, 1999, pp. 295-322; Thibaud, 2002.

17 Judi Hearn, Bermagui By The Sea, Penmark Press, Bermagui, 2004; Nicky Gordon, 'Editorial', South Coast Style, Jan-Feb, 2008, p. 7.

18 Australian Bureau of Statistics, Report 4102.0 Australian Social Trends, 2004,

<http://www.abs.gov.au/ausstats/abs@.NSF/1020492cfcd63696ca2568a1002477b5/df9b2318e79ab 891ca256e9e001fb3e8!OpenDocument>.

19 Mark McKenna Looking for Blackfellas' Point: An Australian History of Place, UNSW Press, Sydney, 2002, pp. 192-201.

20 Interview with author, 19 March 2008.

21 Interview with author, 5 February 2008.

22 Thrift, 'Intensities of Feeling', p. 58.

23 Thrift, 'Intensities of Feeling', p. 60.

24 Les Back, The Art of Listening, Berg, Oxford, 2007, p. 10.

25 Meric Gertler, 'Tacit Knowledge and the Economic Geography of Context, or, the Undefinable Tacitness of Being (There)', Journal of Economic Geography, vol. 3, 2003, pp. 75-99. See also Polyani, The Tacit Dimension.

26 Gary Ansdell, 'Rethinking Music and Community: Theoretical Perspectives in Support of Community Music Therapy', in Mercédès Pavlicevic and Gary Ansell (eds), Community Music Therapy, Jessica Kingsley Publishers, London and Philadelphia, 2004, pp. 91-113; Tia DeNora, Music in Everyday Life, Cambridge University Press, Cambridge, 2000; Michelle Duffy, Gordon Waitt and Chris Gibson, 'Get into the Groove: The Role of Sound in Generating a Sense of Belonging through Street Parades', Altitude, April 2007, available online at <www.altitude21c.com/>; Susan J. Smith, 'Soundscape', Area, vol. 16, 1994, pp. 232-40; Nichola Wood and Susan Smith, 'Instrumental Routes to Emotional Geographies', Social and Cultural Geography, vol. 5, no. 4, 2004, pp. 533-48; Wood, Duffy and Smith.

27 Interview with author, 19 March 2008.

28 Interview with author, 19 March 2008.

${ }^{29}$ Interview with author, 5 February 2008.

30 Sound diary recording, 4 February 2008.

31 Interview with author, 5 February 2008.

32 Interview with author, 7 February 2008.

33 Interview with author, 5 February 2008.

34 Interview with author, 5 February 2008.

35 Wood and Smith.

36 Jack Katz, How Emotions Work, University of Chicago Press, Chicago, 1999, p. 322.

37 Susan J. Smith, 'Performing the (Sound)world', Environment and Planning D: Society and Space, vol. 18, 2000, pp. 615-37; Duffy, Waitt and Gibson; Duffy and Waitt, 'Sound Diaries', forthcoming.

38 See $<$ www.ted.com $>$, the site for the annual Technology Entertainment Design conference.

39 Gorman-Murray and Dowling.

40 Alison Blunt and Robyn Dowling, Home, Routledge, London, 2006, p. 2, quoted in Gorman-Murray and Dowling.

${ }^{41}$ Nira Yuval-Davis, Kalpana Kannabiran, and Ulrike M. Vieten 'Introduction: Situating Contemporary

Politics of Belonging', in Nira Yuval-Davis, Kalpana Kannabiran, and Ulrike M. Vieten (eds), The Situated

Politics of Belonging, Sage, London, 2006, pp. 7-8.

42 Kye Askins, 'Crossing Divides: Ethnicity and Rurality', Journal of Rural Studies vol. 25, 2009, p. 370. 
43 Yuval-Davis, et al, p. 2.

44 Paul Carter, The Sound in Between: Voice, Space, Performance, UNSW Press, Sydney, 1992.

45 Gorman-Murray and Dowling.

46 Interview with author, 5 February 2008.

47 Nigel Thrift, Non Representational Theory Space, Politics, Affect, Routledge, New York, 2008; Thrift, 'Intensities of Feeling', p. 60-8. See also Gordon Waitt and Ruth Lane's discussion of Thrift in 'Fourwheel Drivescapes: Embodied Understandings of the Kimberley', Journal of Rural Studies vol. 23, 2007, pp. 158-9.

48 Waitt and Lane, p. 158. See also Askins.

${ }^{49}$ Askins, p. 366.

50 Duffy et al, 2007.

51 Thibaud, pp. 2, 3.

52 Askins, p. 371.

53 On this point, see also Andrew Gorman-Murray's article in this issue of Cultural Studies Review, 'An Australian Feeling for Snow: Towards Understanding Cultural and Emotional Dimensions of Climate Change', Cultural Studies Review, vol. 16, no. 1, March 2010. 